\title{
Serials Pricing and the Role of the Electronic Journal
}

\section{Paul Metz and Paul M. Gherman}

\begin{abstract}
Editor's note: This article is the third part of a series on scholarly communications and serials prices.

The rapid escalation of serials prices is a serious threat to the system of scientific and scholarly communication. The growth of science, the increase in commercial publishing, and the inherent monopolies enjoyed by journals help account for this problem. Changes in academic reward structures and cooperative action by librarians, individual scientists and scholars, scholarly societies, and university presses are needed. The electronic journal may have a powerful role to play in combating serials inflation if its evolution is shaped thoughtfully and by the right hands.
\end{abstract}

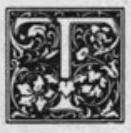

he dilemma of serials pricing, one of the gravest challenges to research libraries in the 1980s, promises to persist as a conundrum seriously threatening our service levels well into the 1990s. It is too soon to say whether this decade will also bring structural changes in scholarly and scientific communication, electronic alternatives to the printed journal, or both. Certainly large economic and technological forces are at work, forces we can, at best, hope to understand and help steer.

Any efforts by the academic community and its librarians to preserve the safe assumption that most researchers can have local access to most of the world's important serial literature most of the time must be based on some understanding of the forces that threaten that historical standard of service. Certainly, intellectual analysis and understanding will be more important than moral alarm or moralistic accusation in solving the problem. However, if we define moral action as the dedicated effort of individuals and institutions to change matters for the public good, moral action will have its place.

\section{HOW WE GOT HERE}

In recent years, scientists and scholars have begun to analyze the pricing problem, spreading an alarm echoing that of librarians, and informing their colleagues that the problems their local libraries face represent a systematic threat to the structure of academic communication. Together with the library literature, these analyses can be drawn on in documenting the several forces whose compound effects have made serials prices escalate with logarithmic speed.

Perhaps the best way to review these forces is by examining the process as its information product flows-from researcher to journal to library. Certainly, one great source of serials inflation has been the enormous increase in scientific and scholarly productivity. According to the physicist Henry N. Barschall, the

Paul Metz is Principal Bibliographer and Paul M. Gherman is University Librarian, both at theUniversity Libraries, Virginia Polytechnic Institute and State University, Blacksburg, Virginia 24062. 
number of abstracts in physics alone leapt from 24,000 in 1962 to 143,000 in 1988 . With the number of physicists doubling and their per capita productivity growing, the number of Physics Review pages quintupled in the same period. ${ }^{1}$ According to Ulrich's, more than 133,000 periodicals are now in print; that is more than twice the roughly 60,000 listed in $1978 .^{2}$ Price increases have finally made it impossible for Association of Research Libraries (ARL) libraries to increase the number of serials to which they subscribe, and there is evidence of a slight decline in the total number of subscriptions among the membership. Together with the increase in titles, the effect has been a reduction in the percentage of the serials universe held by the average ARL library, from nearly 33 percent in 197374 to just over 26 percent in 1986-87..$^{3}$

Such vast increases in scientific and scholarly output represent pages of text, which must appear somewhere if academic communication is to continue unchanged. These additional pages are often absorbed first by the best journals, which dramatically increase the number of pages they publish annually-increases that complicate the calculation of serial inflation rates. Ultimately, of course, journals grow unmanageably large. Simultaneously, the increasing clustering of specialists whose areas divide and subdivide makes a journal's contents too heterogenous to appeal to a single population of readers. At this point, the journal "twigs," becoming two or more discrete publications directed to more specialized audiences.

At the same time that foundations, the government, and individual researchers have been working to effect a great increase in publishable research, the interest of these same parties in subsidizing the publication of research results has waned. Barschall has claimed that for journals such as Physics Review, the result of the dramatic decline in page charges has been a radical shift from author to library as the provider of the majority of revenue. ${ }^{4}$

The enormous increase in the volume of potentially publishable scholarly work has, of course, stimulated a response from publishers eager to provide new avenues for the dissemination of results. Here, things have worked out in the worst way possible; that is, most new journals have been founded by commercial publishers, and commercial publishers have almost invariably charged more than have their private counterparts in societies or universities.

The separate analyses of Paul H. Ribbe and Barschall suggest that the price differential between private and for-profit journals is very large. Ribbe's analysis of journals in mineralogy, petrology, and geochemistry revealed differences of more than three to one. Journals edited by societies, but published privately, were intermediate in price, but closer to the prices of entirely commercial journals. A recent study by Sandra R. Moline also demonstrated significant price differences between journals by commercial and society publishers. ${ }^{5}$ Barschall's analysis in physics concluded that "all the publishers whose journals have low average costs per character or low ratios of cost to impact (factor) are scientific societies or associations, while the publishers whose journals have high costs per character or high ratios of cost to impact are commercial firms." 6 Similar significant price differentials between commercial and society publications have now been documented in crystallography, chemistry, optics, and mathematics. ${ }^{\text {? }}$

Clearly, as science changes, new journals are needed. The very different willingness of private and commercial publishers to launch new journals has been the cause of much "harrumphing" and finger pointing on both sides. Commercial publishers claim that they are merely filling a gap created by the undue conservatism of societies. Robert Shirrell of the University of Chicago Press has acknowledged that societies are indeed financially conservative and are reluctant to launch specialized journals that might appeal to only portions of their memberships and that will inevitably lack the prestige of their flagship journals. ${ }^{8}$ 
While new journals are unquestionably needed, it is not difficult to question the necessity of some of the twigs, leaves, and buds commercial publishers have initiated, generally with initial prices that acquisitions librarians suspiciously regard as "loss leaders." The launching by the Haworth Press of twelve journals with the word marketing in their titles, including Health Marketing Quarterly, Journal of Ambulatory Care Marketing, and Journal of Hospital Marketing, shows that invention can have mothers other than hecessity and that the creation of new titles-without which the morning sun would presumably still appear-is not confined to European publishers of science journals.

When the analysis turns from why some publishers initiate new journals to why they charge more for their offerings, strong differences of opinion emerge. Generally, commercial publishers do not levy page charges, and this source of revenue must be made up. A wide variety of hidden subsidies, most prominently the contributed time of expert reviewers, also favors the not-for-profit journal. Obviously, the necessities of turning a profit and paying taxes impose cost pressures on commercial publishers.

Economists have analyzed the costs of commercial journals and found that objective cost increases do not account for the alarming price increases of recent years. A study conducted by Economic Consulting Services for ARL concluded that "each targeted publisher has increased subscription prices for the sample of titles examined at a much faster rate than the rate at which their costs have increased." The differentials cited for the four most intensively studied publishers (Elsevier, Pergamon, Plenum, and Springer-Verlag) indicated that prices per page had risen from between half again to more than double costs per page. ${ }^{9}$

Outside analyses of costs and profits can quickly lead to a slippery slope of subjectivity and arbitrary accounting conventions, of course. How much profit is enough? Does profit later applied to new risk ventures count as true profit?
Are the costs of mergers and buyouts of profitable journals as legitimate as the costs of paper and ink? How about the costs of luxurious office space or of sending top-level representatives to every library conference to persuade librarians that their prices are fair?

The answers to such questions about accounting are elusive. Ultimately, however, questions about publishers' costs may not be important. It is clear that many scientific and scholarly journals are exempt or nearly exempt from the pressures a perfect market would exert to limit their prices. Each journal, and certainly each prestigious journal, is a monopoly by its nature. Each journal is unique, and no other can substitute for it (imagine telling a faculty representative that to compensate for the cancellation of journal $X$ you would place a second subscription to journal $Y$ ). The monopoly enjoyed by each journal exists not only for the journal as a whole, but for each article. Here, the copyright laws, created to protect authors, are used to protect the monopoly status of publishers and to prohibit the redistribution of property that has been ceded to them by its creators.

\section{Economists have analyzed the costs of commercial journals and found that objective cost increases do not account for the alarming price increases of recent years.}

The ARL report on serials prices summarizes the economic argument well by pointing out that the combination of high fixed costs, low marginal costs per unit, and a limited marketplace necessarily leads to high journal prices. The low elasticity of demand (e.g., the absence of buyer response to price increases) and the inherent monopoly of each title combine to invite high prices and high profit margins. ${ }^{10}$ The best journals have inelastic demand curves because of the repercussions collection development officers anticipate as a consequence of cancellation. Once the po- 
tential for high profitability exists, it is inevitable that it will be seized because, as Malcolm Getz points out, any firm whose management does not maximize profit invites entry into its market by potential competitors and the subsequent disgruntlement of the firm's owners. ${ }^{11}$

One of the most important effects of each journal's monopoly status may be that it frees the process of establishing prices from considerations of cost. If, after all, another publisher could plausibly offer the same journal, a high markup would provide an attractive margin of profit to competitors, who would reason that they could sell the same journal for less and still enjoy good profits. When such market penetration is not feasible, it becomes possible to charge what the market will bear.

Robert L. Houbeck's analysis of differentials between the prices U.K. and U.S. customers pay for British journals provides some evidence that the process of liberating prices from cost, and Instead basing them on value (the utility of a title as expressed by citation counts, number of holding libraries, etc.), may well have begun. In his study of 108 journals published by seven British publishers, Houbeck found that both high prices and high price differentials correlated with various indicators of use and value. $^{12}$

Clearly, the correlation between price and value is still far from absolute; otherwise, Barschall would not have found enormous variation in the ratios of price to citation counts. ${ }^{13}$ But the process may be well underway, especially for commercially published journals. Certainly, the trend toward multitiered pricing of CD-ROMs (whose physical production costs about $\$ 4$ at the margin) and other products whose prices are based on enrollment counts reflects value-based, not cost-based, pricing. If this trend toward value-based pricing continues, it may be difficult to imagine the price limits of the few core journals that have always attracted enormously disproportionate use in each field of science. ${ }^{14}$ By extrapolating current trends, we can conceive of future serials collections confined to a few exorbitantly priced core journals.

The final element explaining the runaway prices for some journals is the vicious circle touched off when librarians are finally forced to begin cancellation. The combination of a narrow subscription base and high fixed costs makes a journal whose profit is marginal (and clearly this excludes many of the most problematic journals) vulnerable to any shrinkage of the subscription base. A. F. Spilhaus, executive director of the American Geophysical Union, explained this phenomenon in a February 1990 presentation to the American Association for the Advancement of Science:

To illustrate the relation of profit to the number of subscribers, consider the following example. If a journal has fixed costs of $\$ 90 \mathrm{~K}$ and incremental costs of $\$ 10$ per volume, then at a subscription price of $\$ 100,1,000$ subscribers produces $\$ 100,000$ or exactly the amount I need to break even. For each additional subscriber, the income is $\$ 100$ and the cost $\$ 10$, so the profit is 90 percent of the income. The flip side is that I can save only $\$ 10$ when I lose a subscriber, so my loss is $\$ 90$. This means that if the journal is close to the break-even point and is price sensitive, the loss of a few subscribers can drive it under. ${ }^{15}$

If the journal is not price sensitivethat is, has the usual low elasticity-the loss of a few subscribers can equally well lead to offsetting increases in the subscription price.

\section{GETTING OUT}

Before we examine the cooperative steps librarians and others can take to reorganize the structure of scholarly communications, it is important to remind ourselves that the elasticity of demand is not an inherent attribute of a journal. Elasticity is defined by consumer action.

As serials inflation forces individual libraries to look hard at their subscription lists, a new emphasis on relative costs and benefits is dawning. Libraries can no longer accept blindly the bias of 
faculty, which is to vote yes or no on titles without respect to their costs, but are learning that a few respectable, but seriously overpriced, journals can be cut to save many less expensive titles. Once libraries establish that there can be life after Nuclear Engineering and Design or Linear Algebra and Its Applications both of which cost more than $\$ 1,000$ though they fail to place in the top 1,000 of journals cited in the science literature, their individual actions will collectively define new elasticity curves for overpriced journals, inevitably forcing publishers to temper their pricing. Publishers should be aware that librarians will not find it so difficult to cut significant journals once they have done it the first time. There are even reports of life after Beilstein.

While such individual actions by libraries will have wholesome effects, larger structural changes are needed. Librarians, scholars, scientists, and other participants in the cycle of scholarly communications have proposed a variety of responses to the serials pricing dilemma. Most of these solutions, which are familiar to most librarians by now and can be quickly summarized, would require the conscious effort of individuals and groups to affect structural changes in scholarly communication itself. Although the impetus of these appeals is moral in that the suggestions arise from a disinterested concern for the vitality of scholarly communication, the appeals do not seek to persuade individual scholars or commercial publishers to change their behaviors. Recognizing the inherent naiveté of such appeals, these authors and speakers have instead suggested changes that would alter reward structures so that self-interested actions would not have the negative consequences they presently do.

One appeal receiving much attention recently is that changes in the reward structure of higher education could reduce the incentive scholars-and perhaps more so, scientists - feel to publish in such prolific quantity. To the extent that promotion and tenure reviews are based on quantity, and not quality, of faculty publication, academicians are motivated to break their research reports into what have been called LPUs (least publishable units). ${ }^{16}$ Because large parts of any research report must discuss, almost as boilerplate, the setting, intellectual context, and methodology of the research, there is great redundancy among the reports. To reduce the great waste this practice causes, colleges and universities are being asked to evaluate candidates for promotion and tenure on the basis of a subset of their publications, which candidates are asked to advance as their best work. ${ }^{17}$

The other major theme of moral appeal has been the argument that librarians, universities, societies, and others do all they can to reverse the trend that has increased the share of academic publishing in the hands of commercial publishers. The ARL report specifically recommends that "ARL should strongly advocate the transfer of publication of research results from serials produced by commercial publishers to existing noncommercial channels. ARL should specifically encourage the creation of innovative nonprofit alternatives to traditional commercial publishers." ${ }^{\text {18 }}$

James C. Thompson's 1988 editorial in College $\&$ Research Libraries-a must read for anyone interested in the serials pricing issue-presents the argument in its simplest and most forceful form:

In the long run, though, we hold the most important cards. The raw material of scholarly publishing, the research and writing, originates within the research community, as does the copyright to it. The commercial publishers are in the information conduit for historical and anachronistic reasons; there is no technical or economic reason why they must remain a part of it. Unthinkable as it might have seemed until very recently, the idea of the academy retaking control of the bulk of scholarly publishing is being forced into consideration by the practices of the commercial publishers themselves. Their bills simply cannot be paid indefinitely, and something must give.

I suspect that the sleeping giant of higher education is about to wake up 
to this problem, and that a long-term solution will be mandated by the faculties and chief administrators of universities and colleges, and by the professional societies. After all, scholarly information originates here in the academy; there's no reason why it shouldn't become a financial asset for education rather than a liability. ${ }^{19}$

The appeal to shift the balance of academic publishing away from commercial publishers has been made to both university presses and scholarly societies. It has come both from the library community and from within the scientific community, whose dawning realization of the violence that publishing practices have done to science may, in time, provide the impetus to resolve the serials dilemma. ${ }^{20}$

What has been unsaid, and perhaps unrecognized, in these appeals is the degree to which their proponents are proposing changes in academic reward systems. One reason that commercial publishers have launched new journals and taken over old ones may be that the editorial work required for journal publication is long and tedious, work that current reward structures do not sufficiently encourage. Commercial journals that are willing to reward editors and readers generously provide competition for reviewers' services when editorial work for society publications is not given tangible reward and, ultimately, libraries pay to underwrite this generosity.

Societies already lack, in many cases, the economies of scale, technical facilities, and marketing experience required to run successful journals. This work can be contracted out, however, to service firms, which can be assured decent profits without being ceded the right to set prices. ${ }^{21}$ It is the intellectual work that cannot be contracted out. When an academic department, scholarly society, or university press decides that it is no longer able to perform this work on a pro bono basis, a journal is well on its way toward becoming a creature of a commercial publishing house. The salient change required to reverse this behavior must, then, be a new recognition by the academic community of the great intellectual contribution that conscientious and informed editors and readers make to scholarly communication and a greater willingness to reward this work with salary, overhead support, and acknowledgment in the promotion and tenure process.

\section{THE ELECTRONIC JOURNAL}

\section{Question One: Will It Come?}

In a sense, the answer to the question of whether the electronic journal (e-journal) will come is "Of course. It has already arrived." For example, Virginia Tech recently launched JIAHR: The Journal of the International Association of Hospitality Research, distributed as a nonprofit operation to paid subscribers. Payment of the annual subscription fee places the subscriber on an e-mail distribution list, which is used to disseminate articles as they appear. It is notable that articles are the units of distribution, as there seems to be no reason to bundle articles into issues. This article has itself cited an electronic newsletter journal, the Newsletter on Serials Pricing, edited by Marcia Tuttle of the University of North CarolinaChapel Hill. While the existence of these journals is encouraging, it is noteworthy that both are new ventures. Their appearance as new publications offers collection development librarians no opportunity for cost avoidance, as there is no prior or co-existing paper journal to cancel. This has typically been the case with electronic journals.

While the e-journal has arrived, and while new journals can be expected to appear at an increasing pace, it does not follow that electronic journals will supplant or supersede exjsting print journals. Đaniel J. Boorstein's remarks in the preservation film Slow Fires are instructive here:

There are very few examples of technologies that have outdated or made totally obsolete their predecessors. We know in our own experience that when people came up with the radio, many people thought that it would make the telephone obsolete. Why should you pay to send a message by 
wire when you could send it over the air free? And then with television it was suggested that of course people wouldn't listen to radio anymore, but I think the statistics show that there are more radios now than there have ever been. There's a rate of increase, with people walking with radios in their ears, which nobody had thought would happen. But they still carry books in their pockets, and they are likely to continue to do so even when it's possible for us to drive our cars while watching television. ${ }^{22}$

If print journals do continue in the future, it would, of course, be a grave error for librarians to have abandoned efforts to solve the present problem of serials pricing. Brett Butler has argued that many key journals will never convert to electronic media:

The 20 percent of journals that represent 80 percent of the journals currently and cumulatively in use will continue to be received by the library in printed form, for two reasons. First, these journals will be the last to abandon print for online, optical disk, or other electronic distribution media. Second, their level of use will require that they initially be distributed and available for use in their original form. ${ }^{23}$

If it is true that journal prices increasingly reflect value and not cost to produce, it follows that the 20 percent of the journals Butler identifies as critical may gradually become the 20 percent that drive up the majority of subscription costs for libraries.

The crucial point seems to be that publishers, especially commercial publishers, have no incentive to give away what they can now sell. Perhaps the critical point about the print medium is that it converts intellectual property into a physical commodity whose use can be limited and monitored and whose replication and redistribution is inconvenient and unsatisfactory. These limitations in reproducibility and transportability, while serious drawbacks to libraries and their users, are highly valuable strategic advantages to publishers. There is cur- rently no mechanism in place to prevent the duplication and redistribution of electronic text. Without such a mechanism, publishers of profitable journals will regard the electronic journal with the same fear and suspicion that the entertainment industry has had of dual VCRs or digital audio tape, both of which have faced legal and economic roadblocks despite their technological feasibility.

\section{Publishers, especially commercial publishers, have no incentive to give away what they can now sell.}

In considering the fears that publishers express about easily copied media, we must recognize that although publishers have unquestionably exploited the copyright protection that is mainly intended to safeguard authors, they do have legitimate needs in this area. No journal can be produced for the three or four cents a page required for wholesale photocopying of its contents. To waive all copyright protection for publishers would be to expose them to wholesale redistribution of their products, redistribution that would allow them no recompense for the managerial and editorial work they contribute to scholarly communications.

\section{Question Two: If It Comes, Will It Be Villain or Savior?}

Eldred Smith has made it clear that electronic technology has the potential either to add new and costly expenditures to the research library's burdens or to provide less costly alternatives to existing investments. ${ }^{24}$ This observation implies a warning that the electronic journal may become part of the problem rather than part of the solution.

The first question to ask in considering the economic impact of the electronic journal is how much journal publishers will be able to save by publishing electronically. This question reduces to an effort to estimate the proportion of journal costs which are print-bound. Paper, 
ink, postage, and typesetting are the specific costs the electronic medium avoids. But we should not exaggerate the savings journals will realize by avoiding print. Journals accepting camera-ready copy or electronic text meeting Standard Generalized Markup Language (SGML) standards already avoid most typesetting costs. Also, we should not assume that the costs of electronic distribution will remain negligible, depending on national telecommunications policy as it emerges through deliberations over the National Research and Education Network. Still, it does appear that the costs avoided when a journal migrates from paper to an electronic format are considerable. In the surprising absence of current hard data, the Economic Consulting Services study used "reasonably detailed" U.S. data from 1975, which indicated the following distribution of costs for journal production: ${ }^{25}$

TABLE 1

ESTIMATED COSTS OF JOURNAL PRODUCTION, 1975

\begin{tabular}{lr}
\hline Expense & $\%$ \\
\hline Editing labor & 25 \\
Typesetting & 25 \\
Printing labor & 25 \\
Paper & 10 \\
Postage & 10 \\
Other & 5 \\
$\quad$ Total & 100 \\
\hline
\end{tabular}

If these cost percentages still pertained, well over half of the costs of journal publication would be associated with paper and could be avoided by electronic publication. However, it is likely that as editing, managerial, and capital costs have soared, the traditional costs of printing have become less significant. Butler estimates that actual printing accounts for only 10 percent of costs, with the managerial and editing costs that persist in any format accounting for about 60 percent. ${ }^{26}$

To base our estimates of the effect of electronic publication on publisher costs alone would be to ignore our earlier conclusion that value, not cost, is the key factor in establishing journal prices. If we assume that commercial publishers will not convert from paper to electronic publication until they can monitor and restrict use at least as well as they can today, then these same publishers will be as free as they currently are to base price on value or need rather than on cost.

One possible outcome- one we could expect if the worst possible scenario continues to be the one that will transpireis the dual publication of each journal. There would be nothing to stop commercial publishers from "prepublishing" solely in electronic format, and then selling the archival and canonical version of the same journal in print a year or so later. The paper version could quite likely contain modifications based on electronic dialogues between readers and authors of the original version. $\mathrm{Li}$ braries would be under heavy pressure from their research communities to subscribe to the first (electronic) edition, but would also require the second (paper) edition if they were to fulfill their traditional goal of making materials available to students, nonspecialists, and future users.

Fears such as these have led to expressions of deep suspicion. Spilhaus makes worried allusions to Robert Maxwell's recruitment of top executives skilled in electronics from the not-for-profit publishing arena, and Thompson questions the motivations behind the ADONIS project. $^{27}$

\section{Question 3: How Can We Shape the Electronic Journal so that It Is a Benefit to Scholarly Communications?}

Although commercial publishers may well fear the electronic journal, it may offer a window of opportunity for academia to recapture control of scholarly communication because the e-journal is not a replacement for the paper journal, but a new means of communication. Sharon J. Rodgers and Charlene S. Hurt, in an editorial in the Chronicle of Higher Education, envisioned a new, fluid, and evolving means of communication be- 
tween scholars that adds increased value to the paper journal. ${ }^{28}$ The e-journal will add speed and spontaneity to communication that the paper journaleanmot attain. Its distribution can be instantaneous, responses to authors can be appended to the original author's work, and the work itself can evolve in light of commentary by the community of scholars in a specific field. Indeed, the e-journal will reestablish the community of scholars in a new dynamic way.

\section{The e-journal is not a replacement for the paper journal, but a new means of communication.}

Eventually, sound and animation will enhance the medium. The power of hypertext will give new depth to scholarly works, and the unit of information transfer will change from the issue to the article, with hypercard stacks leading the reader to backup data or related paths to the central thesis of each scholarly idea.

The true power of the e-journal is that it retains information in its fluid state and resists its conversion to a commodity, as occurs with the print version. Harland Cleveland has pointed out that information does not behave like a commodity; it leaks, increases in value as it is shared, is difficult to control, and cannot be used up..$^{29}$ The e-journal amplifies these qualities. This is why commercial publishers have been so reticent to enter into e-journal publishing, and why copyright protection cannot survive in the electronic networked environment. The academic community can use this power of the e-journal to its advantage.

Academia can readily enter the e-journal environment because, unlike commercial publishers, it has nothing to lose. Academicians have already given their information away to commercial publishers and have lost control of it via the copyright law, which protects primarily publishers, not authors. Commercial publications, in turn, transform the information into a commodity and sell it back to academia at exorbitant prices. In the e-journal environment, academia can continue to give its information away, but it will return to academicians many times multiplied and enhanced at no or very little cost.

Steven W. Gilbert and Peter Lyman, in their article "Intellectual Property in the Information Age," ask several important philosophical and ethical questions, such as, "In what ways should the results of intellectual work be considered property? Whose?" and "Should interests in property impede access to ideas?" ${ }^{30}$ The answer to each of these questions seems clear. Access to ideas must supersede ownership of ideas, and intellectal work should remain the property of the author or the agency that supports the work of authors.

Anew model for dealing with intellectual property already resides in our library culture; it is called interlibrary loan. Librarians freely lend most of their books to other libraries, with the assumption that other libraries will reciprocate. The e-journal can work in the same way. Each university-sponsored e-journal could be offered free or nearly free over the electronic network in exchange for e-journals sponsored by other universities. The system would not be completely equitable, but neither is interlibrary loan. Generally, net lenders see it as their responsibility to share their resources with less fortunate libraries in return for the value the total system of exchange offers them. The same model can apply to the e-journal. In this new environment of shared information, the smallest and poorest library can have the same access to information riches as the wealthy library, and at very little marginal cost. All the smaller institutions have to do to enjoy the riches of electronic ideas is develop their telecommunications and computing infrastructure.

At a recent meeting of the Coalition for Networked Information (CNI), keynote speaker John Witherspoon from San Diego State University recalled the creation of the Corporation for Public Broadcasting in the $1960 \mathrm{~s}$. At that time, about twenty-five universities had edu- 
cational television stations. With funding through the Corporation for Public Broadcasting, there is today no congressional district without access to publicly supported television. Likewise, there is an equally strong network for sharing programming among these stations.

\section{Access of ideas must supersede own- ership of ideas, and intellectual work should remain the property of the author or the agency that supports the work of authors.}

The same model might be proposed for publishing. A Corporation for Public Publishing could be developed to support university presses and other nonprofit e-publishers of scholarly and scientific information. Federal support could encourage standardization of epublications and the free sharing of this information. Indeed, it could be made a requirement that all federally supported research be published via a member of the CPP. There needs to be the recognition that free access to federally supported information is in the national interest and that it should not fall into the hands of for-profit publishers.

If universities are to take on the responsibility of fostering and supporting the e-journal and sharing these publications freely, ultimately, cost must be a driving force. Will the costs of supporting freely shared information via the ejournal be more economically viable than supporting the current system of information bondage to the commercial publishers? There has been strong debate as to whether the e-journal will offer cost savings over the print journal and, as mentioned earlier, data are scant. Publishers have noted that the actual cost of typesetting and printing is only a minor element in the total cost of producing a journal. To gain an understanding of this issue, Virginia Tech established an Office of Scholarly Communication, which developed a program of scholarly journal publishing in both print and electronic media. Over the past two years, Virginia
Tech has taken over the publication of the International Journal of Analytical and Experimental Modal Analysis-a highquality scientific publication in paperfrom a scholarly society. It has also launched the JIAHR: Journal of the International Association of Hospitality $R e$ search, an electronic publication.

Although it is too early to tell conclusively, the cost differential is significant. The typesetting, printing, and mailing costs of the paper journal make the overall costs well over 50 percent higher than the e-journal's. Both journals enjoy the same pro bono reviewing and editing by faculty, as do many for-profit journals. Each has a managing editor; however, the e-journal's editing cost is less due to the ease of editing e-text.

Because academia already fully supports the cost of commercial journals, the e-journal freely shared could realize significant savings, which could be put into developing the telecommunications and computing infrastructure on our campuses, resulting in ancillary benefits. Beyond the direct savings generated from subscriptions, there are other savings that accrue to universities by reducing the library costs of shelf space to house the journals, as well as the costs of new buildings. The costs of binding, theft, mutilation, and handling are also direct cost savings to libraries and, ultimately, provide universities with the added benefit of ubiquitous and assured availability. These savings can be used to expand the information stock, instead of to support an ever decreasing, but costly, information stock.

Although libraries are close to the fulcrum of the problem of rising serial prices, they are far from the fulcrum of the solution. The responsibility for the creation of an alternative scholarly communications system rests with the faculty and administrators of all major universities in this country and beyond. Libraries have been successful in sounding the alarm; now we must plant the seeds of the solution. The e-journal could rightfully be grown in our university presses. However, the presses historically have not involved themselves in 
journal publishing, but have concentrated primarily on monographs. They do not have the same cultural values of sharing information as do libraries because they have to keep a closer eye on the bottom line and cannot afford to subvene too many publications. Presses have not developed the networks libraries have, nor do they adhere to a system of standards as do libraries. Also, university presses, unlike libraries, have no experience in archiving their products, which could become a major requirement of the publisher of the future. Libraries have, by necessity, forged closer relationships with computing and telecommunications organizations on campus. Therefore, libraries might well be the singular organization to foster and develop the e-journal on campuses where no press exists. Where they do exist, we might join with them in the establishment of the e-journal. These new e-journals would reside in the academic departments of the universities and be edited by the teaching and research faculty. The libraries could help foster these journals by assisting with standards, distribution, subscriptions, and-most of all-archiving back files. Each library might then become part of the virtual electronic library by maintaining these back files on the network for ready access by the community of scholars. ${ }^{31}$ Libraries, along with utilities like OCLC, could then support the directory of network locations for the archives of all e-journals.

\section{A Corporation for Public Publishing could be developed to support univer- sity presses and other nonprofit e-publishers.}

The creation of the e-journal will involve a major cultural and value change on the part of the faculty, who must accept this new medium as a valid means of being vested in the academy. Faculty will have to become comfortable with surrendering copyright for their articles to the university, not the publisher. It will mean the acceptance of information as a shared resource, instead of a commodity. It will mean that libraries will truly have to embrace access to information over ownership and that we will have to develop new control mechanisms for information in this environment. We will have to become the archivists of record for those e-journals that are created on our campuses and, at the same time, libraries will have to become nodes of the virtual library of tomorrow.

\section{Libraries have been successful in sounding the alarm; now we must plant the seeds of the solution.}

Libraries may have more power to lend credibility to the new e-journal than we realize. As we integrate e-journals into the information structure by listing them in our OPACs, and as we insist that they be indexed by the commercial indexing services, our teaching and research faculty may more readily accept them as a valid means of scholarly communication. We are the stewards of our cultural heritage, and we can make the e-journal a part of that heritage if we choose to.

The new coalition of ARL, EDUCOM, and CAUSE brings together a much larger segment of the academic community with like goals. The Coalition for Networked Information started by these groups could have the creation of e-journals as one of its goals. Allegiances like those of OCLC and AAAS also foster new partnerships between the library community and scholarly societies in the creation of the e-journal. Many more such joint partnerships must be developed between the scholarly community and libraries as we forge not only the new paradigm of libraries, but of scholarship.

There are many technical and organizational issues as well as value issues to be addressed as we create this new system. Many universities and libraries are not yet part of the internet. In the interim, an organization like OCLC might use its telecommunications system to de- 
liver e-journals to libraries not on the internet. Indeed, one strategic advantage academia has is that commercial publishers do not yet have ready access to networks for delivery of the e-journal. An organization like OCLC might also host the network directory of e-journals and serve as the billing and subscription agent for our universities. Current printers are too slow and limited to print the e-journal, especially bit-mapped images of pages. Xerox has recently announced a new product called Zenith, which is a high-quality digital photocopier capable of producing off-set print quality. ${ }^{32} \mathrm{De}-$ vices like these may soon make on-demand publishing a reality as they turn the e-journal into high-quality print to be sent to faculty members via campus mail, especially when telecommunications or desktop workstations may not yet be available.

A task force has just been established at the Virginia Tech library to determine how it integrates the e-journal into library procedures and processes. How will bibliographers determine which ones the library should subscribe to? Will it list them in its OPAC? How will the patron locate them? Should the library include the e-journal's internet address in the OPAC? How do patrons receive or claim an e-journal? Should the library create a full text file of these journals on its computer or simply allow its patrons to access the host computer files over the internet if it exists? Should the patron be able to go to the full text from the OPAC by a simple key stroke? How many copies of an e-text should be stored on the university system? These are just a few of the questions the library will need to answer.

\section{CONCLUSION}

Time is short for universities to reestablish themselves as controllers of the information stock they themselves create. Once commercial publishers recognize that universities might attempt to reestablish their rightful role in scholarly communication, they will undoubtedly try to subvert the effort. They currently have significant economic leverage over librarians and our faculty, and they have the momentum of the status quo behind them. They have the prestige of the established journals and long-standing relationships with many of our most recognized faculty. It must be our role to show these same faculty that it is in their long-term best interest to join the ranks of those who would change the system. The problem is that many of our older established faculty have yet to embrace the technology that will make the e-journal possible, and they will see the e-journal as lacking credibility. We must bring them to the realization that they can no longer surrender their intellectual property to the for-profit sector. Instead, academic and scholarly societies can control scientific and technical information and share it freely. But we must act now to change the social and cultural values among the teaching faculty, as well as develop the conceptual and institutional means of promoting e-publications.

\section{REFERENCES AND NOTES}

1. Henry H. Barschall, "The Cost-Effectiveness of Physics Journals," Physics Today 41:5659 (July 1988).

2. Gregg Sapp and Peter G. Watson, "Librarian-Faculty Relations during a Period of Journal Cancellations," Journal of Academic Librarianship 15:285-89 (Nov. 1989).

3. Ann Okerson, "Of Making Many Books There Is No End: Report on Serials Prices for the Association of Research Libraries," report to Association of Research Libraries, 1989, passim.

4. Henry H. Barschall, comments summarized in Deana L. Astle, "Association of College and Research Libraries Discussion Group on Serials Pricing," Newsletter on Serials Pricing Issues 17 (Feb. 16, 1990). Electronic newsletter; access via E-mail TUTTLE@UNC.BITNET. 
5. Paul H. Ribbe, "Assessment of Prestige and Price of Professional Publications," American Mineralogist 73:449-69 (1988); Sandra R. Moline, "The Influence of Subject, Publisher Type, and Quantity Published on Journal Prices," Journal of Academic Librarianship 15:12-18 (Mar. 1989).

6. Barschall, "Cost-Effectiveness," p.57.

7. Okerson, "Of Making Many Books," p.30.

8. Robert Shirrell, comments summarized in Astle, "Discussion Group on Serials Pricing."

9. Economic Consulting Services Inc., "A Study of Trends in Average Prices and Costs of Certain Serials over Time," report to Association of Research Libraries, 1989, p.1, 2, 22.

10. Okerson, "Of Making Many Books," p.36.

11. Malcolm Getz, "How Journals Are Priced," The Bottom Line 2(4):37-39.

12. Robert L. Houbeck, Jr., "British Journal Pricing: Enigma Variations, or What Will the U.S. Market Bear?" Library Acquisitions: Practice and Theory 10(3):183-97 (1986).

13. Barschall, "Cost-Effectiveness," p.57.

14. Eugene Garfield, "Citation Analysis as a Tool in Journal Evaluation," Science 178:471-79 (Nov. 3, 1972).

15. A. F. Spilhaus, Jr., "The Financial Crisis in Science Libraries: The Scientific Community Is the Problem and the Solution," Newsletter on Serials Pricing Issues 21 (Apr. 27, 1990). Electronic newsletter; access via E-mail TUTTLE@UNC.BITNET.

16. Deana L. Astle, "With Sci/Tech Journals, Hidden Costs Cost a Lot," Library Acquisitions: Practice and Theory 12(2):163-67 (1988), p.164.

17. Okerson, "Of Making Many Books," p.33; Peggy Johnson, "Crisis in Scholarly Communications, What You Can Do," Library Line: An Occasional Newsletter of the University of Minnesota Libraries, cited in Newsletter on Serials Pricing Issues 18 (Mar. 1990). Electronic newsletter; access via E-mail TUTTLE@UNC.BITNET.

18. Okerson, "Of Making Many Books," p.42.

19. James C. Thompson, "Journal Costs: Perception and Reality in the Dialogue," College E Research Libraries 49:481-82 (Nov. 1988).

20. Okerson, "Of Making Many Books," passim.

21. A. F. Spilhaus, Jr.'s presentation specifically mentioned the Allen Press in Lawrence, Kansas as an excellent provider of "marketing programs and all sorts of other assistance in publications management for the society that is too small or does not care to have that kind of expertise on staff," Spilhaus, "The Financial Crisis."

22. Daniel J. Boorstein in Slow Fires on the Preservation of the Human Record, (video cassette) (Santa Monica, Cal.: American Film Fdn., 1987).

23. Brett Butler, "Scholarly Journals, Electronic Publishing, and Library Networks: From 1986 to 2000," Serials Review 12:47-52 (Summer/Fall 1986).

24. Eldred Smith, "Resolving the Serials Dilemma," College E Research Libraries 52:235 (May 1991).

25. Economic Consulting Services, Inc., "A Study of Trends," p.8.

26. Butler, "Scholarly Journals," p.49.

27. Spilhaus, "The Financial Crisis"; Thompson, "Journal Costs," 481-82.

28. Sharon J. Rodgers and Charlene S. Hurt, "How Scholarly Communications Should Work in the 21st Century," Chronicle of Higher Education 36(7):A56 (Oct. 18, 1989).

29. Harlan Cleveland, "Information as a Resource," Futurist 16(6):36-37 (Dec. 1982).

30. Stan W. Gilbert and Peter Lyman, "Intellectual Property in the Information Age," Change 21(3):28 (May/June 1989).

31. The term "virtual library" is used in the same context that "virtual memory" is used in computer science. The user will perceive that the library has a single physical location when, in reality, it is dispersed across many computers residing on the network.

32. "High-Tech Gamble, Xerox Tries to Shed Its Has-been Image with Big New Machine," Wall Street Journal 216(57): Section A: 1, 8 (Sept. 20, 1990). 